\title{
Prediction of Ipsilateral and Contralateral Cervical Lymph Node Metastasis in Unilateral Papillary Thyroid Carcinoma
}

\author{
El Sayed R. Ahmed*, Said H. Bendary, Mohamed Esmat, Ibrahim M. Hasan, Mohamed F. Abd \\ Elmoaty, Mohamed R. Abd Elhamid \\ Department of General Surgery, Faculty of Medicine, Al Azhar University \\ *Corresponding author: El Sayed R. Ahmed, Email: gogoseka1@ gmail.com
}

\begin{abstract}
Background: Surgical therapy is the cornerstone of treatment in patients with papillary thyroid cancer (PTC). Surgical therapy in PTC includes hemithyroidectomy or total thyroidectomy (TT) and, in cases of lymph node metastases, cervical lymph node dissection (CLND). The inclusion of prophylactic central compartment neck dissection (pCCND) as a new approach in the management of patients with PTC with clinically negative cervical lymph nodes raised controversies among the endocrine surgeons and predictive factors for central lymph node (CLN) metastasis in unilateral PTC cases not well defined.

Objectives: To investigate the risk factors associated with CLNM in clinical lateral cervical lymph node-negative ( $\mathrm{cNO}$ ) and analyze the rate of ipsilateral and contralateral CLN metastasis in unilateral PTC cases in Al Azhar University Hospitals in the period from May 2016 till June 2018.

Patients and Methods: A prospective case-control descriptive study was performed to investigate the research questions during the period from the $1^{\text {st }}$ of May 2016 till the end of June 2018 in Al-Azhar University Hospitals. A total of 40 selected patients suffering from papillary thyroid with clinically negative cervical lymph nodes who have received total thyroidectomy with bilateral CLND. The clinicopathological features of PTC patients with respect to sex, age, observation, tumor diameter, multifocality, extrathyroidal invasion, lymphovascular invasion and capsular invasion.The risk factors of CLNM were analyzed by Chi-squared test and multivariate logistic regression model.

Results: Ipsilateral CLN metastasis were present in 47.5\% (19/40). Results analysis showed that males patients with tumor size $(>1 \mathrm{~cm})(\mathrm{P}=0.027$; OR, 2.153), age <45 years old $(\mathrm{P}=0.017$; OR, 2.009) and capsular invasion $(\mathrm{P}=0.018 ; \mathrm{OR}=0.730)$ were the predictors of ipsilateral $\mathrm{CLN}$ metastasis.Contralateral CLN metastasis were present in $17.5 \%$ (7/40) and prelaryngeal lymph node (LN) metastasis ( $\mathrm{P}=0.008$; $\mathrm{OR}, 13.333)$ and ipsilateral CLN metastasis $(\mathrm{P}=0.051$; $\mathrm{OR}, 9.231)$, pretracheal lymph nodes $(\mathrm{P}=0.051$; $\mathrm{OR}$, 9.231), lymphovascular invasion $(\mathrm{P}=0.043$; OR, 5.113) and ETE $(\mathrm{P}=0.05$; OR, 4.901) independently predicted contralateral CLN metastasis.

Conclusion: For the high-risk PTC patients with CLNM, prophylactic CLND may be beneficial. Nevertheless, the present data was a single center prospective analysis, and the long-term prognostic factors including recurrence rate and mortality rate were lacking. Therefore, the results of this research may only serve as a tool in predicting CLNM.
\end{abstract}

Keywords: central lymph node, central lymph node metastasis, thyroid papillary carcinoma

\section{Introduction}

Papillary thyroid cancer (PTC) accounted for $>90 \%$ of all the new thyroid cancers ${ }^{(1)}$. PTC appears as an irregular solid or cystic mass or nodule in a normal thyroid parenchyma. Although its differentiated characteristics, papillary carcinoma may be overtly or minimally invasive. Papillary tumors have a propensity to lymphatic spread but are less likely to invade blood vessels ${ }^{(2)}$. The most common presentation of PTC is an asymptomatic thyroid nodule or a palpable cervical lymph node ${ }^{(3)}$. The biopsy using fineneedle aspiration (FNAB) can be considered the first-line diagnostic procedure for detecting thyroid nodule. Surgery is the gold slandered treatment of papillary thyroid cancer. Approximately 4-6 weeks after surgical thyroid removal, patients may have radioiodine therapy to detect and destroy any metastasis and residual tissue in the thyroid ${ }^{(4)}$. The lymphatic drainage of the thyroid and its pattern is relatively consistent, and the spread of lymph node metastasis in PTC takes place in a stepwise fashion. Generally, cervical lymph node metastasis in PTC involves the central compartment first, followed by the ipsilateral 
lateral compartment and then the contralateral lateral compartment and mediastinal lymph node ${ }^{(5)}$.

PTC affect cervical lymph nodes in $30-80 \%$ of affected patients. Metastasis to cervical lymph nodes in PTC patients was reported to be independent factor for locoregional recurrence, and it also has an adverse impact on survival, especially in older patients ${ }^{(6)}$.

Prophylactic central lymph node dissection (CLND) in patients with PTC remains controversial and predictive factors for central lymph node (CLN) metastasis in unilateral PTC cases are not well defined ${ }^{(7)}$.

\section{Patients and Methods}

A total of 40 selected patients suffering from papillary thyroid cancer were treated in AlAzhar University hospitals from 2016 to 2018. All included patients were diagnosed with PTC by preoperative fine-needle aspiration biopsy or by intraoperatively on frozen section. Preoperative ultrasound (US) and computerized tomography (CT) scan were performed to identify patients with unilateral PTC and no suspicious LN in the neck.

Patients included in this study had all of the following criteria: Unilateral Papillary thyroid carcinoma diagnosed preoperative by FNAC or intraoperative by frozen section. No suspicious $\mathrm{LN}$ in the neck preoperative by neck US or CT or MRI. Patients were excluded if they had any of the following criteria: Previous neck surgery. Synchronous neck pathology. Medically unfit for surgery. Patients with other pathologic types of thyroid malignancy. Patients with recurrent thyroid cancer (local or nodal metastases). Patients with distant metastasis. External radio therapy on the neck. Patients undergoing unilateral CLND.

Patients had PTC in isthmus or bilateral lobes. A total of 40 patients were finally enrolled into our study. Total thyroidectomy and bilateral central neck dissection for all patients. We defined the pretracheal, prelaryngeal (Delphian) and ipsilateral paratracheal lymphnodes as ipsilateral central compartment, and contralateral paratracheal lymph nodes as contralateral central compartment. The central compartment was limited by the hyoid bone superiorly, the innominate vein inferiorly, the carotid sheaths in both sides laterally and the prevertibral fascia dorsally and was divided into three nodes ites:pretracheal and prelaryngeal (Delphian), ipsilateral paratracheal and contralateral paratracheal lymph nodes.
Bilateral CLND is defined as the removal of CLNs [including pretracheal, paratracheal (ipsilateral and contralateral), prelaryngeal and perithyroidal groups] as well as nodes along the recurrent laryngeal nerves. Specimens were sent for histopathological examination according to their location. The electronic clinical and pathological records collected included sex, age, tumorsize, extrathyroidal invasion, capsular invasion, lymphovascular inavasion, chronic lymphatic thyroiditis, focality, location if unifocal, and central compartment LN involvement. Moreover, the number of total and positive LNs in each central region was also determined. All patients provided informed consents. We did routine laryngoscopy to all patients whether preoperative or postoperative. The study was approved by the Ethics Board of Al-Azhar University.

\section{Statistical analysis}

The collected data was revised, coded, tabulated and introduced to a PC using Statistical package for Social Science (IBM Corp. Released 2011. IBM SPSS Statistics for Windows, Version 20.0. Armonk, NY: IBM Corp). Data was presented, and suitable analysis was done according to the type of data obtained for each parameter.

Presentation of quantitative data as mean, SD and range, description of qualitative variables as number and percentage. Chi-square test was used to compare qualitative variables. Two sample t-test was used to compare quantitative variables between independent groups in parametric data. Paired t-test was used to compare between two means measured twice for the same study group. McNemar test was used assess the statistical significance of the difference between a qualitative variable measured twice for the same study group. Pvalue was considered significance when $<0.05$.

Results

\section{Patient characteristics and surgical parameters}

The study involved 40 patients with PTC.There were 29 women $(72.5 \%)$ and 11 men $(27.5 \%)$ with mean age $39.28 \pm 11.13$ years, and a range of 21 to 59 years. Of these patients, $67.5 \%$ $(27 / 40)$ were $<45$ years of age, and $32.5 \%$ $(13 / 40)$ were $\geq 45$ years of age. The median size of primary tumor was $0.9 \mathrm{~cm}$ (range, $0.3-$ $4 \mathrm{~cm}), 30$ patients $(75.0 \%)$ had a primary tumor 
$\leq 1 \mathrm{~cm}$,and $10(25.0 \%)$ had a primary tumor $>1$ $\mathrm{cm}$.

Among 40 patients, 19 patients $(47.5 \%)$ had ipsilateralCLN metastasis, 7 patients $(17.5 \%)$ had contralateral CLN metastasis, 6 (15.5\%) had prelaryngeal LN metastasis, and 18 (45.0\%) had pretracheal LN metastasis.

Univariate and multivariate analyses of risk factors

In univariate analysis, ipsilateral CLN metastasis was more prevalent in patients who were male, $<45$ years of age, or had a tumor $>1$ $\mathrm{cm}(\mathrm{P}<0.05)$. Multivariate analysis revealed that tumor size $>1 \mathrm{~cm}(\mathrm{P}=0.016$; $\mathrm{OR}, 2.005)$ and age $<45$ years old $(\mathrm{P}=0.031 ; \mathrm{OR}, 1.539)$ were the predictive factors of ipsilateral CLN metastasis (Table 2).
The rate of contralateral CLN metastasis was 13.3\%. Contralateral CLN metastasis was significantly associated with prelaryngeal $\mathrm{LN}$ metastasis $(\mathrm{P}=0.002)$, pretrachealLN metastasis $(\mathrm{P}=0.025)$, and ipsilateral CLN metastasis $(\mathrm{P}=0.025)$ by univariate analysis (Table 3$)$. Table 4 shows the results of multivariate analysis. Prelaryngeal $\mathrm{LN}$ metastasis $(\mathrm{P}=0.008$; OR, 13.333) and ipsilateral CLN metastasis $(\mathrm{P}=0.051 ; \quad \mathrm{OR}, 9.231)$ Lympho vascular invasion $(\mathrm{P}=0.043$; $\mathrm{OR}, 5.113)$. ETE $(\mathrm{P}=$ 0.031 ; OR, 4.901) were the independent predictive factors of contralateral CLN metastasis. Chronic lymphatic thyroiditis were not significantly related to the presence ipsilateral or contralateral CLN metastasis.

Table 1. Logistic regression analysis for predictors of ipsilateral

\begin{tabular}{|l|l|l|l|l|l|}
\hline Variables & $\boldsymbol{\beta}(\mathrm{SE})$ & P value & OR & 95\% CI (OR) & \\
\cline { 5 - 7 } & & & & Lowr & upper \\
\hline Sex & $0.545(0.343)$ & 0.112 & 0.580 & 0.296 & 1.136 \\
\hline Age <45 y & $0.617(0.287)$ & 0.017 & 2.009 & 1.307 & 2.946 \\
\hline $\begin{array}{l}\text { Tumor size >1 } \\
\text { cm }\end{array}$ & $0.696(0.290)$ & 0.027 & 2.153 & 3.538 & 3.535 \\
\hline Capsular invasion & $0.838(0.197)$ & 0.018 & 0.730 & 1.707 & 2.346 \\
\hline
\end{tabular}

Table 2.a Clinicopathologic factors in relation to ipsilateral central lymph node (CLN) metastasis

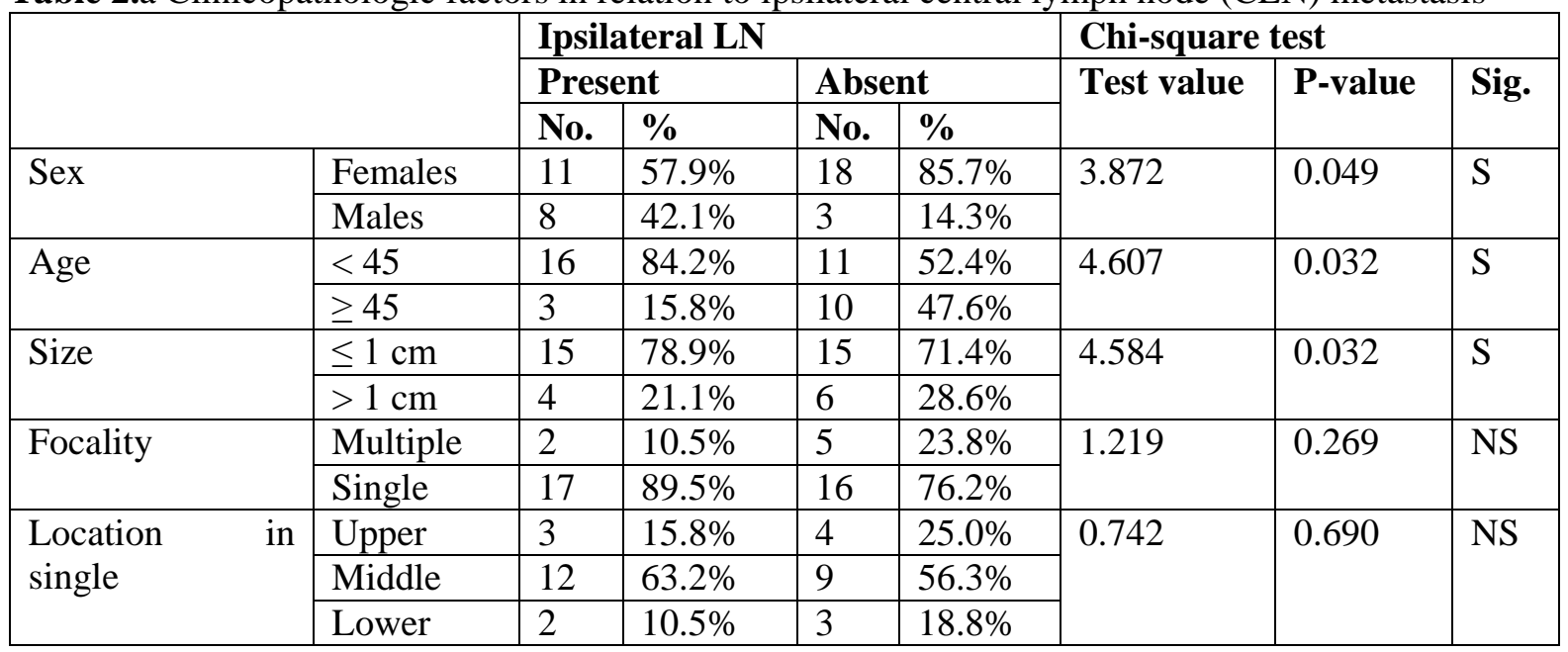


Cervical Lymph Node Metastasis in Unilateral Ipsilateral and Contralateral of Prediction...

Table 2.b Clinicopathologic factors in relation to ipsilateral central lymph node (CLN) metastasis

\begin{tabular}{|c|c|c|c|c|c|c|c|c|}
\hline & \multicolumn{4}{|c|}{ Ipsilateral LN } & \multicolumn{3}{|c|}{ Chi-square test } \\
\hline & & \multicolumn{2}{|c|}{ Present } & \multicolumn{2}{|c|}{ Absent } & \multirow[t]{2}{*}{ Test value } & \multirow[t]{2}{*}{ P-value } & \multirow[t]{2}{*}{ Sig. } \\
\hline & & No. & $\%$ & No. & $\%$ & & & \\
\hline \multirow[t]{2}{*}{ Capsular invasion } & Positive & 6 & $31.6 \%$ & 14 & $66.7 \%$ & \multirow[t]{2}{*}{4.912} & \multirow[t]{2}{*}{0.027} & \multirow[t]{2}{*}{$\mathrm{S}$} \\
\hline & Negative & 13 & $68.4 \%$ & 7 & $33.3 \%$ & & & \\
\hline \multirow[t]{2}{*}{ Lymph. Vascular } & Positive & 1 & $5.3 \%$ & 5 & $23.8 \%$ & \multirow[t]{2}{*}{2.691} & \multirow[t]{2}{*}{0.101} & \multirow[t]{2}{*}{ NS } \\
\hline & Negative & 18 & $94.7 \%$ & 16 & $76.2 \%$ & & & \\
\hline \multirow[t]{2}{*}{ Thyroiditis } & Positive & 12 & $63.2 \%$ & 12 & $57.1 \%$ & \multirow[t]{2}{*}{0.150} & \multirow[t]{2}{*}{0.699} & \multirow[t]{2}{*}{ NS } \\
\hline & Negative & 7 & $36.8 \%$ & 9 & $42.9 \%$ & & & \\
\hline \multirow[t]{2}{*}{ ETE } & Positive & 7 & $36.8 \%$ & 8 & $53.3 \%$ & \multirow[t]{2}{*}{0.925} & \multirow[t]{2}{*}{0.336} & \multirow[t]{2}{*}{ NS } \\
\hline & Negative & 12 & $63.2 \%$ & 7 & $46.7 \%$ & & & \\
\hline
\end{tabular}

Table 3 Demographic and clinicopathologic characteristics of patients with unilateral PTC

\begin{tabular}{|l|l|l|}
\hline Variable & Females & No. $=40$ \\
\cline { 2 - 3 } & Males & $29(72.5 \%)$ \\
\hline Age & Mean \pm SD & $11(27.5 \%)$ \\
\hline & Range & $21.28 \pm 11.13$ \\
& $<45$ & $27(67.5 \%)$ \\
\hline \multirow{2}{*}{ Size } & $\geq 45$ & $13(32.5 \%)$ \\
& Median (IQR) & $0.9(0.8-1.75)$ \\
& Range & $0.3-4$ \\
& $\leq 1 \mathrm{~cm}$ & $30(75.0 \%)$ \\
\hline Focality & $>1 \mathrm{~cm}$ & $10(25.0 \%)$ \\
\hline Location in single & Multiple & $7(17.5 \%)$ \\
& Single & $33(82.5 \%)$ \\
\hline Number of dissected nodes & Upper & $7(17.5 \%)$ \\
\hline Ipsilateral paratracheal lymph nodes & Middle & $21(52.5 \%)$ \\
\hline Contralateral paratracheal lymph nodes & Lower & $5(12.5 \%)$ \\
\hline Pretracheal lymph nodes & Mean \pm SD & Range \\
\hline Prelaryngeal lymph nodes & $5.5 \pm 3.7$ & $1-21$ \\
\hline Chronic lymphatic thyroiditis & $4.0 \pm 3.4$ & $1-17$ \\
& $3.9 \pm 3.6$ & $1-21$ \\
\hline Extrathyroidal invasion & $0.8 \pm 1.3$ & $1-6$ \\
\hline Lymphovascular invasion & Positive & $9(22.5 \%)$ \\
& Negative & $31(77.5 \%)$ \\
\hline Capsular invasion & Positive & $24(60.0 \%)$ \\
& Negative & $16(40.0 \%)$ \\
\hline & Positive & $6(15.0 \%)$ \\
& Negative & $34(85.0 \%)$ \\
\hline & Positive & $20(50.0 \%)$ \\
& Negative & $20(50.0 \%)$ \\
\hline
\end{tabular}

Table4. Logistic regression analysis for predictors of contralateral

\begin{tabular}{|c|c|c|c|c|c|c|c|}
\hline & \multirow[t]{2}{*}{ B } & \multirow[t]{2}{*}{ S.E. } & \multirow[t]{2}{*}{ Wald } & \multirow[t]{2}{*}{ P-value } & \multirow[t]{2}{*}{ Odds ratio (OR) } & \multicolumn{2}{|c|}{ 95\% C.I. for OR } \\
\hline & & & & & & Lower & Upper \\
\hline Ipsilateral & 2.223 & 1.137 & 3.819 & 0.051 & 9.231 & 0.993 & 85.775 \\
\hline Prelaryngeal & 2.590 & 0.975 & 7.063 & 0.008 & 13.333 & 1.974 & 90.071 \\
\hline Pretracheal & 2.223 & 1.137 & 3.819 & 0.051 & 9.231 & 0.993 & 85.775 \\
\hline Lymph. Vascular & 2.094 & 1.591 & 2.306 & 0.043 & 5.113 & 0.771 & 67.829 \\
\hline ETE & 2.167 & 1.843 & 2.612 & 0.031 & 4.901 & 0.853 & 71.095 \\
\hline
\end{tabular}


Table 5. Clinicopathologic factors in relation to contralateral central lymph node (CLN) metastasis

\begin{tabular}{|c|c|c|c|c|c|c|c|c|}
\hline & \multicolumn{4}{|c|}{ Contralateral LN } & \multicolumn{3}{|c|}{ Chi-square test } \\
\hline & & \multicolumn{2}{|c|}{ Present } & \multicolumn{2}{|c|}{ Absent } & \multirow[t]{2}{*}{ Test value } & \multirow[t]{2}{*}{ P-value } & \multirow[t]{2}{*}{ Sig. } \\
\hline & & No. & $\%$ & No. & $\%$ & & & \\
\hline Ipsilateral & $\begin{array}{l}\begin{array}{l}\text { Positive } \\
\text { negative }\end{array} \\
\text {. }\end{array}$ & $\begin{array}{l}6 \\
1\end{array}$ & $\begin{array}{l}85.7 \% \\
14.3 \%\end{array}$ & $\begin{array}{l}13 \\
20\end{array}$ & $\begin{array}{l}39.4 \% \\
60.6 \%\end{array}$ & 4.969 & 0.025 & $\mathrm{~S}$ \\
\hline Prelaryngea & $\begin{array}{l}\text { Positive } \\
\text { negative }\end{array}$ & $\begin{array}{l}4 \\
3\end{array}$ & $\begin{array}{l}57.1 \% \\
42.95 \%\end{array}$ & $\begin{array}{l}3 \\
30\end{array}$ & $\begin{array}{l}9.1 \% \\
90.9 \%\end{array}$ & 9.236 & 0.002 & HS \\
\hline Pretracheal & \begin{tabular}{|l|} 
Positive \\
Negative
\end{tabular} & $\begin{array}{l}6 \\
1\end{array}$ & $\begin{array}{l}85.7 \% \\
14.3 \%\end{array}$ & $\begin{array}{l}13 \\
20\end{array}$ & $\begin{array}{l}39.4 \% \\
60.6 \%\end{array}$ & 4.969 & 0.025 & $\mathrm{~S}$ \\
\hline Capsular invasion & \begin{tabular}{|l|} 
Positive \\
Negative \\
\end{tabular} & $\begin{array}{l}4 \\
3 \\
\end{array}$ & $\begin{array}{l}57.1 \% \\
42.9 \% \\
\end{array}$ & $\begin{array}{l}16 \\
17 \\
\end{array}$ & $\begin{array}{l}48.5 \% \\
51.5 \% \\
\end{array}$ & 0.173 & 0.667 & NS \\
\hline Lymph. Vascular & \begin{tabular}{|l|} 
Positive \\
Negative
\end{tabular} & $\begin{array}{l}3 \\
4\end{array}$ & $\begin{array}{l}42.9 \% \\
57.1 \%\end{array}$ & $\begin{array}{l}3 \\
30\end{array}$ & $\begin{array}{l}9.1 \% \\
90.9 \%\end{array}$ & 5.164 & 0.023 & $\mathrm{~S}$ \\
\hline Thyroiditis & $\begin{array}{l}\text { Positive } \\
\text { Negative }\end{array}$ & $\begin{array}{l}2 \\
5\end{array}$ & $\begin{array}{l}28.6 \% \\
71.4 \%\end{array}$ & $\begin{array}{l}7 \\
26\end{array}$ & $\begin{array}{l}21.2 \% \\
78.8 \%\end{array}$ & 0.179 & 0.672 & NS \\
\hline ETE & \begin{tabular}{|l|} 
Positive \\
Negative
\end{tabular} & $\begin{array}{l}1 \\
6\end{array}$ & $\begin{array}{l}14.3 \% \\
85.7 \%\end{array}$ & $\begin{array}{l}20 \\
13\end{array}$ & $\begin{array}{l}60.6 \% \\
39.4 \%\end{array}$ & 4.969 & 0.026 & $\mathrm{~S}$ \\
\hline Sex & \begin{tabular}{|l|} 
Females \\
Males \\
\end{tabular} & $\frac{3}{4}$ & $\begin{array}{l}42.9 \% \\
57.1 \%\end{array}$ & $\begin{array}{l}26 \\
7\end{array}$ & \begin{tabular}{|l|}
$78.8 \%$ \\
$21.2 \%$
\end{tabular} & 3.739 & 0.053 & NS \\
\hline Age & \begin{tabular}{|l|}
$<45$ \\
$>45$
\end{tabular} & $\frac{5}{2}$ & $\begin{array}{l}71.4 \% \\
28.6 \%\end{array}$ & $\frac{22}{11}$ & $\begin{array}{l}66.7 \% \\
33.3 \%\end{array}$ & 0.060 & 0.806 & NS \\
\hline Size & \begin{tabular}{|l}
$\leq 1 \mathrm{~cm}$ \\
$>1 \mathrm{~cm}$
\end{tabular} & $\frac{4}{3}$ & $\begin{array}{l}57.1 \% \\
42.9 \%\end{array}$ & $\frac{26}{7}$ & \begin{tabular}{|l|}
$78.8 \%$ \\
$21.2 \%$
\end{tabular} & 1.443 & 0.230 & NS \\
\hline Focality & \begin{tabular}{|l} 
Multiple \\
Single
\end{tabular} & $\frac{2}{5}$ & $\begin{array}{l}28.6 \% \\
71.4 \%\end{array}$ & $\begin{array}{l}5 \\
28\end{array}$ & \begin{tabular}{|l|}
$15.2 \%$ \\
$84.8 \%$
\end{tabular} & 0.72 & 0.396 & NS \\
\hline Location in single & \begin{tabular}{|l|} 
Upper \\
Middle \\
Lower
\end{tabular} & $\begin{array}{l}3 \\
2 \\
0\end{array}$ & $\begin{array}{l}42.9 \% \\
28.6 \% \\
0.0 \% \\
\end{array}$ & $\begin{array}{l}4 \\
19 \\
5\end{array}$ & \begin{tabular}{|l|}
$14.3 \%$ \\
$67.9 \%$ \\
$17.9 \%$ \\
\end{tabular} & 5.59 & 0.061 & NS \\
\hline
\end{tabular}

\section{Discussion}

Differentiated thyroid carcinoma is known as one of the most common endocrine malignancy. We investigated clinical and pathologic features in 40 patients with unilateral PTC with no suspicious cervical lymph nodes. The incidence of PTC has increased rapidly in the past years; small PTCs account for most new diagnoses, which may result from the increased detection of small tumors that are incidentally noted on diagnostic imaging studies ${ }^{(\mathbf{1})}$.

The recent increased usage of imaging procedures, such as neck ultrasound, has identified a large number of small thyroid nodules, with a similar increasing trend in the proportion of PTMC in all PTC patients ${ }^{(2)}$. The variation in the prevalence of cervical LNM across different studies may result from the differences in the number of patients, the different rationales (therapeutic or prophylactic) underlying the use of LND in PTMC, and the subtle variations in the surgical completeness among surgeons and the number of lymph nodes in histopathological findings detected among pathologists ${ }^{(\mathbf{3})}$.

Male sex was a risk factor for LNM, which suggests that males require specialized neck checkups of the thyroid to enable the early detection of thyroid tumors ${ }^{(4)}$.

Patient age is known to be an important risk factor for patients with PTCm more than 1 $\mathrm{cm}^{(5)}$. A greater tumor size was significantly associated with LNM, which was consistent with a previous study ${ }^{(6)}$. Our results revealed that the evaluation of LLNM was not simply dependent on the primary tumor size but on the results of the preoperative imaging examination, especially in the PTMC patients with increased tumor size ${ }^{(7)}$.

The rate of contralateral CLN metastasis was $17.5 \%$ (7/40). Of these patients, $2(5 \%)$ had isolated contralateral CLN metastasis without ipsilateral CLN involvement in our study. Multivariate analysis in our study showed that ipsilateral CLN metastasis was an independent predictor of contralateral CLN metastasis, 
which was consistent with previous reports ${ }^{(\mathbf{8})}$. Additionally, we also found the rate of contralateral CLN metastasis was significantly higher in cases with histologically proven metastasis to the prelaryngeal $\mathrm{LN}(\mathrm{P}=0.008)$. It is accepted that prelaryngeal $\mathrm{LN}$ positivity was associated with further nodal metastasis to the central and lateral neck compartments and with heavier nodal burden ${ }^{(9)}$.

As our study reported, the incidence of ipsilateral CLN metastasis was high, while that of contralateral CLN metastasis was relatively low, with most metastases observed in patients with tumors size $>1 \mathrm{~cm}$. This may help us in detection of the extent of prophylactic CLND in the treatment of unilateral PTC. Despite the ATA guidelines do not recommend elective central neck dissection in patients with small, non-invasive cN0 PTCs or in most patients with follicular cancer, our findings indicate that patients with larger tumor size $(>1 \mathrm{~cm})$ should undergo unilateral or bilateral CLND with thyroidectomy in the initial surgery and for most patients with tumor size $>1 \mathrm{~cm}$, total thyroidectomy and ipsilateral CLND should be sufficient $^{(\mathbf{1 0})}$.

Our results revealed that. hypocalcemia was more commonly seen in PTC patients after thyroidectomy and CLND than after thyroidectomy alone. In our study, transient hypoparathyroidism was found in 35\% (14/40), which was similar to those observed in previous studies $(26.6-49.5 \%)^{(11)}$. Considering the mentioned morbidities in preceding paragraphs, preoperative identification of patients with PTC at greater risk of metastases to the central compartment would be valuable. Sometimes LN metastasis in the central compartment cannot be detected by palpation and does not appear abnormal in preoperative imaging. Preoperative US have been reported as a rapid, low-cost, noninvasive, and reliable method for detecting neck metastasis of head and neck cancer, but with a limitation because of low sensitivity ${ }^{(\mathbf{1 2})}$.

To evaluate the status of CLN metastasis accurately, intraoperative palpation or inspection has emerged as an alternative approach to preoperative imaging. Intraoperative frozen biopsy appears to be a supplementary, safe and efficacious tool to guide the use and determine the extent of CLND $^{(13)}$. Our study highlighted that therapeutic bilateral CLND can be considered in patients with a tumor size $>1 \mathrm{~cm}$ especially in the presence of prelaryngeal $\mathrm{LN}$ and ipsilateral CLN metastasis on frozen section analysis. Furthermore, we indicateed that CLN metastasis is common in PTC patients with clinically node negative neck and prophylactic ipsilateral CLND. This may be an optional procedure and should be considered for patients with a tumor size $>1 \mathrm{~cm}$; however, we cannot detect the cause-and-effect relationship between the risk and variables due to the nature of the design of our study which is a retrospective.

Due to the short duration of follow-up, tumor recurrence and survival after central compartment dissection were not well studied. Further investigation with a long follow-up time is necessary to determine whether the studied parameters are associated with prognosis.

\section{Limitations of the study}

Despite the study has reached its objectives, there were some limitations. At first, due to the time limit and small sample size, as the research was conducted only on patients who are attending the Al-Azhar hospital clinic. Second, absence of comparative group, it is a descriptive study.

\section{Conclusion}

Ipsilateral CLN metastasis was reported to be the most common pattern of CLN metastasis in unilateral PTC patients with clinically nodenegative neck. Tumor size $>1 \mathrm{~cm}$ was an independent predictive factor of ipsilateral CLN metastasis. Furthermore, prelaryngeal LN metastasis and ipsilateral CLN metastasis were the independent predictive factors of contralateral CLN metastasis. Prophylactic ipsilateral CLND can be an optional procedure and should be considered for patients with a tumor size $>1 \mathrm{~cm}$. Therapeutic bilateral CLND should be considered in patients with a tumor size $>1 \mathrm{~cm}$ and especially in the presence of prelaryngeal LN or ipsilateral CLN metastasis on frozen section analysis.

\section{References}

1. Eun YG, Lee YC, Kwon KH (2014): Predictive factors of contralateral paratracheal lymph node metastasis in papillary thyroid cancer: prospective multicenter study. Otolaryngol Head Neck Surg., 150:210-5.

2. Kim HJ, Kim NK, Choi JH, Sohn SY, Kim SW, Jin SM et al. (2013): Associations between body mass index and clinico- 
pathological characteristics of papillary thyroid cancer. Clin Endocrinol ., 78(1):134-40.

3. Lee KE, Chung IY, Kang E et al. (2013): Ipsilateral and contralateral central lymph node metastasis in papillary thyroid cancer: patterns and predictive factors of nodal metastasis. Head Neck ,35:672-6.

4. Pellegriti G, Frasca F, Regalbuto C et al. (2013): Worldwide increasing incidence of thyroid cancer: update on epidemiology and risk factors. J Cancer Epidemiol., 2013:965212.

5. Nam IC, Park JO, Joo YH et al. (2013): Pattern and predictive factors of regional lymph node metastasis in papillary thyroid carcinoma: a prospective study. Head Neck, 35:40-5.

6. Rotstein L (2009): The role of lymphadenectomy in the management of papillary carcinoma of the thyroid. J Surg Oncol., 99:186-8.

7. Sadowski BM, Snyder SK, Lairmore TC (2009): Routine bilateral central lymph node clearance for papillary thyroid cancer. Surgery, 146:696-703.

8. Raffaelli M, De Crea C, Sessa L et al. (2012): Prospective evaluation of total thyroidectomy versus ipsilateral versus bilateral central neck dissection in patients with clinically node-negative papillary thyroid carcinoma. Surgery, 152:957-64.
9. Raffaelli M, De Crea C, Sessa L et al. (2013): Can intraoperative frozen section influence the extension of central neck dissection in cN0 papillary thyroid carcinoma? Langenbecks Arch Surg., 398:383-8.

10. Palestini $\mathrm{N}$, Borasi A, Cestino $\mathrm{L}$ et al. (2008): Is central neck dissection a safe procedure in the treatment of papillary thyroid cancer? Our experience. Langenbecks Arch Surg., 393:693-8.

11. Giordano D, Valcavi R, Thompson GB et al. (2012): Complications of central neck dissection in patients with papillary thyroid carcinoma: results of a study on 1087 patients and review of the literature. Thyroid, 22:911-7. 12. Chisholm EJ, Kulinskaya E, Tolley NS (2009): Systematic review and meta-analysis of the adverse effects of thyroidectomy combined with central neck dissection as compared with thyroidectomy alone. Laryngoscope, 119:11359.

13. Park JP, Roh JL, Lee JH et al. (2014): Risk factors for central neck lymph node metastasis of clinically noninvasive, nodenegative papillary thyroid microcarcinoma. Am J Surg., 208:412-8. 